\title{
A formação ética e o autoconhecimento para a formação de professores(as) em direitos humanos e ciências naturais
}

\author{
The ethics training and self-Knowledge for training teachers in
}

human rights and teaching natural sciences

La formación ética y el autoconocimiento para la formación de docentes en derechos humanos y ciencias naturales

HANSLIVIAN CORREIA CRUz BONFIM (Da

ORLINEY MACIEL GUIMARÃES (DDb

\section{Resumo}

Este ensaio teórico tem como objetivo discutir sobre a formação continuada de professores(as) de Ciências Naturais, dos anos iniciais do ensino fundamental, voltada à formação ética e ao autoconhecimento, tendo como propósito uma Educação em Direitos Humanos. Para o desenvolvimento deste ensaio, foi realizado um levantamento bibliográfico em livros, periódicos acadêmicos e artigos, que teve como objetivo aprofundar a temática apontada. Considera-se que as atitudes pedagógicas dos(as) professores(as) podem ser influenciadas pelas disposições construídas ao longo de sua história, assim é importante que o(a) docente reflita sobre essas disposições (habitus), visando uma formação ética, política e crítica, que leva ao desenvolvimento de práticas pedagógicas mais voltadas para uma Educação em Direitos Humanos.

Palavras-chave: Formação Continuada. Ensino de Ciências. Educação em Direitos Humanos.

\footnotetext{
a Prefeitura Municipal de Curitiba, Curitiba, PR, Brasil. Doutora em Educação, e-mail: hansbonfim@hotmail.com

b Universidade Federal do Paraná (UFPR), Curitiba, PR, Brasil. Doutora em Ciências, e-mail: orli.guimaraes@gmail.com
} 


\section{Abstract}

This theoretical essay aims to discuss the continuing education of Natural Sciences teachers in the early years of elementary education, focused on ethics training and selfknowledge, whit the principle of Human Rights Education. For the development of this essay, which aimed to deepen the subject matter pointed out. It is considered that the pedagogical attitudes of teachers may be influenced by the dispositions built throughout their history, so it is important that teachers reflect on these dispositions (habitus), aiming at an ethical, political and critical education, that lead to pedagogical practices more focused on human rights education.

Keywords: Continuing. Science teaching. Human Rights Education.

\section{Resumen}

Este ensayo teórico tiene como objetivo discutir la formación continua de los (las) docentes de Ciencias Naturales, desde los primeros años de la escuela primaria, centrada en la formación ética y el autoconocimiento, con el propósito de una Educación en Derechos Humanos. Para el desarrollo de este ensayo, se realizó un relevamiento bibliográfico en libros, revistas académicas y artículos, con el objetivo de profundizar el tema señalado. Se considera que las actitudes pedagógicas de los (las) docentes pueden verse influenciadas por las disposiciones construidas a lo largo de su historia, por lo que es importante que el (la) docente reflexione sobre estas disposiciones (habitus), apuntando a una formación ética, política y crítica, que conduzca al desarrollo de prácticas pedagógicas más enfocadas en la Educación en Derechos Humanos.

Palabras clave: Formación Continua. Enseñanza de ciencias. Educación en derechos humanos.

\section{Introdução}

O ensino de Ciências Naturais é um direito da criança nos anos iniciais do Ensino Fundamental, como é previsto pela Lei de Diretrizes e Bases da Educação Nacional no 9.394/96. Nesse sentido, cabe aos(às) professores(as) ampliarem os conhecimentos dos(as) estudantes, considerando a faixa etária com a qual trabalha, a partir de estratégias educativas e de um planejamento adequado. O componente curricular de Ciências Naturais poderá contribuir para que os conhecimentos dos(as) estudantes sejam ampliados, fazendo com que, cada vez mais, esses(as) educandos(as) se aproximem do conhecimento científico, sendo esse um instrumento importante para a formação cidadã. Consideramos que para se desenvolver uma formação cidadã é necessário ao(à) professor(a) abordar temas integradores no ensino de Ciências Naturais, como o tema Direitos Humanos e Cidadania, indo ao encontro das Diretrizes Curriculares Nacionais para a Educação em Direitos Humanos (BRASIL, 
2012). No contexto brasileiro, são constatadas inúmeras injustiças sociais, as quais também afetam o âmbito escolar, caracterizando, por isso, a importância de se refletir sobre essa temática no Ensino de Ciências nos anos iniciais, o qual tem como objetivo desenvolver nos(as) estudantes as atitudes, as formas de pensar e os valores baseados no respeito e na tolerância, já que muitos conteúdos de Ciências são possíveis de se articularem com temáticas que envolvem Direitos Humanos e Cidadania (BONFIM, GUIMARÃES, 2020).

Sendo assim, consideramos que essa articulação dos conteúdos de Ciências naturais com temáticas relacionadas aos Direitos humanos somente é possível se o(a) professor(a) compreender o que são direitos humanos e entender a importância de se desenvolver uma cultura relacionada a eles. Entendemos que as atitudes pedagógicas dos(as) professores(as) podem ser influenciadas pelas disposições construídas ao longo de sua história, consideramos importante que o(a) professor(a) reflita sobre essas disposições e, diante disso, avaliamos que os momentos de formação continuada podem ser espaços para essas reflexões sobre a ação educativa. Assim, os cursos de formação continuada seriam oportunidades para essa reflexão e problematização desse habitus, os quais podem estar carregados de alguns preconceitos que conduzam a ações voltadas para intolerância, podendo desencadear inclusive atitudes de não aceitação do outro. Enfim, são questões que irão, de uma forma ou de outra, influenciar os discursos, as ações dos(as) professores(as) no contexto escolar e, principalmente, a sua relação com os conteúdos e práticas em sala de aula.

Este artigo consiste em um ensaio teórico, fundamentado na literatura da área, o qual expõe ideias e pontos de vista dos autores, com objetivo de discutir a formação continuada de professores(as) de Ciências Naturais, dos anos iniciais, voltada à formação ética e ao autoconhecimento, tendo como princípio uma Educação em Direitos Humanos, sem ter a intenção de explorar o tema de forma exaustiva. Para isso, realizamos um levantamento bibliográfico, utilizando diversas fontes como: livros, publicações periódicas e artigos científicos (CARVALHO et al., 2019), a fim de atingir o objetivo do artigo. Nesse sentido, o artigo foi divido nos seguintes tópicos: Socialização dos professores: a constituição do habitus; Formação continuada de professores e o desenvolvimento profissional; Formação de professores voltada para os Direitos Humanos e Ensino de Ciências Naturais. 
Para a discussão sobre a constituição do habitus, nos fundamentamos em Bourdieu (2003, 2011, 2013), Setton (2002a, 2016), e Gimeno Sacristán (1999), pois são autores que tratam sobre o processo de socialização, conceito importante quando se discute sobre a formação docente. Para a discussão sobre o desenvolvimento profissional, nos embasamos em Marcelo Garcia (1999), Gimeno Sacristán (1999), e Imbernón (2016), os quais versam sobre a formação continuada do(a) professor(a). Sobre a Formação de professores voltada para os Direitos Humanos e Ensino de Ciências Naturais, foram utilizados, principalmente, Contreras (2002), Imbernón (2016) e Arroyo $(2007,2015)$, que defendem a formação ética e o autoconhecimento dos(as) professores(as); Candau e Sacavino (2013) que trazem subsídios para uma formação de professores para atuarem na Educação em Direitos Humanos; e Bueno e colaboradores (2017), Gobbi (2010) e Pizarro, Barros e Lopes Junior (2016), que discutem alguns aspectos sobre o ensino de Ciências nos anos iniciais.

\section{Socialização dos (as) professores (as): formação do habitus}

Considera-se que as ações realizadas pelos(as) professores(as) são baseadas em disposições construídas durante o processo de socialização, ou seja, ao longo da história do indivíduo, a qual, muitas vezes, determinará as práticas dos(as) professores(as) no seu contexto social, bem como a sua ação docente. A partir dessa perspectiva, compreende-se que a identidade do(a) professor(a) se constitui a partir da sua história e das experiências que ele teve em sua trajetória de vida, portanto, em seu mundo social. A partir dessa compreensão, discutiremos sobre a constituição do habitus no processo de socialização do agente, para entendermos sobre a importância desse conceito para as práticas realizadas pelos docentes no contexto escolar.

O habitus é produzido por estruturas específicas de um tipo particular de meio, como as condições materiais de existência de uma determinada classe social. Bourdieu (2003) destaca que o agente constrói disposições que são construídas ao longo da história e que essas disposições, propensões e concepções presentes no agente podem ser definidas como habitus, que são: 
[...] disposições duráveis, estruturas estruturadas predispostas a funcionar como estruturas estruturantes, isto é, como princípio gerador e estruturador de práticas e das representações que podem ser objetivamente "reguladas" e "regulares" sem ser o produto da obediência de regras, objetivamente adaptadas a seu fim sem supor a intenção consciente dos fins e o domínio expresso das operações necessários para atingilos e coletivamente orquestradas, sem ser o produto da ação organizadora de um regente (BOURDIEU, 2003, p. 61).

As disposições podem ser compreendidas como um sistema de propensões e escolhas que fazemos no contexto social em que estamos inseridos. Essas disposições são geradas a partir de estruturas estruturadas, que são condicionantes sociais, presentes na sociedade e que estão fora do agente. A estrutura estruturante é como algo que se desenvolve para fora, ou seja, algo que interfere no babitus do indivíduo. Hey (2017, p. 191) explica que, “como máquinas cognitivas, os agentes não são simplesmente o efeito de uma estrutura, pois estão engendrados na construção de um espaço amalgamado resultante de percepções e ações anteriores”.

Portanto, o habitus é constituído a partir do processo de socialização, podendo esta ser compreendida, de acordo com Berger e Luckmann (2014, p. 169), como "a introdução do indivíduo no mundo objetivo de uma sociedade, ou de uma parte dela". Em relação ao processo de socialização, Setton (2002a, p. 67) explica que na sociedade contemporânea há diferentes instâncias socializadoras, dando origem a "um campo de socialização híbrido e diversificado", constituindo, dessa forma, um novo sujeito social, a partir de uma nova configuração que contribui para a construção de um babitus. Nessa perspectiva, a construção do habitus do agente não se dá apenas a partir dos processos de socialização primária, que seriam a família e a escola (socialização secundária), mas a partir também das influências da mídia nesse processo de construção. E complementa que, “[...] para o bem ou para o mal, a cultura de massa está presente em nossas vidas, transmitindo valores e padrões de conduta, socializando muitas gerações" (SETTON, 2002b, p. 109). Assim, o processo de socialização, de acordo com esta autora, pode ser definido como "um espaço plural de múltiplas relações sociais" (SETTON, 2002b, p. 109).

Para Setton (2016), habitus é um conceito que precisa ser "circunstanciado historicamente, definição que expressa a mediação indivíduo e sociedade, é princípio explicativo das práticas e das representações de indivíduos em conjunturas específicas e particulares" (SETTON, 2016, p. 53). Nessa perspectiva, o agente não é passivo no 
processo de socialização, ele pode ser considerado como um agente reflexivo de sua história e, portanto, não é uma simples reprodução mecânica dos condicionantes iniciais (BOURDIEU, 2013). Bourdieu (2011) considera que o habitus irá gerar as práticas dos agentes e que cada classe em particular é condicionada, a partir de condições específicas de existência, e essas condições irão construir o habitus.

Bourdieu destaca que as práticas culturais podem ser compreendidas como toda forma de "comportamento cotidiano, toda ação que faz parte da rotina dos indivíduos ou dos grupos, toda prática que, compondo do dia-a-dia de cada um, explicita um modo de ser e fazer dos agrupamentos humanos" (SETTON, 2016, p. 59). Como, por exemplo, as formas de alimentar-se, de vestir-se, de realizar escolhas referentes ao lazer ou turismo, opções voltadas para livros, artes, etc. Sendo que essas escolhas não são neutras, mas sim resultado de uma história social, do processo de socialização específica que irá confirmar o pertencimento a uma determinada classe social. Assim, no campo social há diferentes classe sociais, as quais possuem diferentes tipos de capital, gerando, portanto, diferentes estilos de vida.

Setton (2016) explica que a estrutura social pode ser considerada como um sistema hierarquizado de poder e privilégios, sendo que esses são determinados pelas relações materiais e econômicas e, também, pelas relações simbólicas e/ou culturais entre os indivíduos. Partindo dessa visão, a posição em que o grupo ou o indivíduo se encontra será "determinada pelo volume e composição de um ou mais capitais adquiridos e ou incorporados ao longo das suas trajetórias sociais" (SETTON, 2016, p. 61). A autora também destaca que a manutenção da ordem social vigente, injusta e hierarquizada, é proveniente não apenas da distribuição inadequada dos diferentes capitais, mas também da forma como ocorre o processo de "transmissão desses poderes e recursos distintos. Nesse sentido, chama-se a atenção para as diferentes condições materiais e simbólicas de socialização dos grupos destacando duas instâncias educativas fundamentais nesse processo, a família e a escola” (SETTON, 2016, p. 62). Em relação à família, Bourdieu (2011) destaca que essa "tem um papel determinante na manutenção da ordem social, na reprodução, não apenas biológica, mas social, isto é, na reprodução da estrutura do espaço social e das relações sociais" (BOURDIEU, 2011, p. 131). 
Nessa perspectiva, se pode considerar que a família, enquanto primeira instância socializadora, e a escola são espaços que produzem valores morais e identitários, gerando dessa maneira um “modus operandi de pensamento, além de um sistema de disposições que orientaria as escolhas de uma variedade infinita de práticas de cultura e seus diferentes estilos" (SETTON, 2016, p. 63). Assim, para Setton (2016), o habitus é um conceito que possibilita conciliar a oposição entre a "realidade exterior e as realidades individuais, seria, portanto, a troca constante entre o mundo objetivo e o mundo subjetivo das individualidades" (SETTON, 2016, p. 63).

A partir do conceito de habitus, descrito por Bourdieu e Setton, o agente constituirá diferentes formas de ver o mundo, crenças, atitudes, maneiras de se relacionar com o outro e de se comportar diante de diversas situações do contexto social. Essas formas de ver o mundo, de se comportar diante de diferentes situações, formas de falar e de pensar, são influenciadas pelas diferentes instâncias socializadoras, sendo elas a família, a escola, a igreja, as associações de bairro, os clubes e a própria mídia que transmite informações relacionadas aos padrões de vida, aos conceitos estéticos, ao que é considerado certo e errado, ao que é belo ou feio, etc. Consideramos diante disso, que essas disposições poderão estar baseadas, muitas vezes, em uma educação contrária aos valores sociais e humanos indispensáveis para se viver e se criar uma cultura em direitos humanos.

Partindo dessa premissa, entendemos que essas disposições irão influenciar as ações do(a) professor(a) na sala de aula, bem como suas considerações sobre o que é uma Educação em Direitos Humanos. Penna (2012, p. 201) destaca que as práticas realizadas pelos(as) docentes são influenciadas por disposições adquiridas pelo processo de socialização familiar e que conhecer esse habitus familiar contribui para entender as "razões práticas presentes nas ações das professoras, uma vez que o babitus adquirido no âmbito familiar funciona como esquema classificatório e princípio de construção do mundo". E ainda, conclui que a origem social de professores e professoras "é relevante para a compreensão de disposições presentes no habitus familiar, uma vez que essas aprendizagens dizem respeito às condições de vida e aos valores e aspirações a elas vinculados" (PENNA, 2012, p. 201).

Sendo assim, considera-se que as ações realizadas pelos (as) professores(as) são baseadas em disposições já construídas ao longo do processo de socialização docente. 
Essas disposições construídas, ao longo da história do indivíduo, determinarão as ações dos(as) professores(as) na sua vida social e na sua atuação enquanto docente. Para Gimeno Sacristán (1999, p. 72), “o que fazemos depende do legado de outros e do que cada um realizou até esse momento; agimos de acordo com as marcas de nossa biografia e das ações dos outros" (GIMENO SACRISTÁN, 1999, p. 72).

A partir dessas colocações sobre como as atitudes pedagógicas dos(as) professores(as) podem ser influenciadas pelas disposições construídas ao longo de sua história, consideramos importante que o(a) professor(a) reflita sobre essas disposições e, diante disso, avaliamos que os momentos de formação, tanto inicial quanto continuada, podem ser espaços para essas reflexões sobre a ação educativa. Avaliamos que os cursos de formação continuada podem ser gatilhos para a mudança desse habitus, o qual é, muitas vezes, influenciado por questões voltadas para o preconceito, para a não aceitação do “outro", para a intolerância, enfim, questões que irão de uma forma ou de outra influenciar os discursos, as ações dos(as) professores(as) no contexto escolar e, principalmente, a sua relação com os conteúdos e sua prática em sala de aula. Acreditamos que a formação continuada deve ter como intuito o desenvolvimento profissional docente, temática que será discutida no próximo tópico.

\section{Formação continuada e desenvolvimento profissional}

De acordo com Marcelo Garcia (1999), compreende-se a formação de professores(as) como um processo, o qual deve ser organizado e sistematizado, uma vez que o mesmo deve ocorrer de forma intencional. A formação poderá acontecer de forma individual, quando esse(a) docente realiza, por exemplo, um curso à distância, ou poderá acontecer em um grupo de professores(as). Essa última forma é a que Marcelo Garcia (1999) considera a com maior potencialidade para mudanças e, portanto, mais interessante, já que esta formação poderá consistir no desenvolvimento profissional centrado nos interesses e necessidades dos professores envolvidos nesse processo. A formação de professores(as) tem como meta levar a uma aquisição de conhecimento, tanto para os(as) professores(as) em formação quanto para aqueles que já exercem a docência, com o aperfeiçoamento da 
competência profissional. Assim, para Marcelo Garcia (1999), a formação de professores(as) pode ser compreendida da seguinte forma:

[...] é a área de conhecimento, investigação e de propostas teóricas e práticas que, no âmbito da Didáctica e da Organização Escolar, estuda os processos através dos quais os professores - em formação ou em exercício - se implicam individualmente ou em equipa, em experiências de aprendizagem através das quais adquirem ou melhoram os seus conhecimentos, competências e disposições, e que lhes permite intervir profissionalmente no desenvolvimento do seu ensino, do currículo e da escola, com o objetivo de melhorar a qualidade da educação que os alunos recebem (MARCELO GARCIA, 1999, p. 26).

A partir dessa citação, compreendemos que a formação do(a) professor(a) tem como foco a melhoria da qualidade da educação para benefício do(a) estudante, mediante a aprendizagem do(a) docente, para a aquisição de competências, conhecimentos e disposições (MARCELO GARCIA, 1999). Neste artigo, o cerne é a formação continuada dos(as) professores(as), considerando-a como fundamental para a aprendizagens de disposições indispensáveis para se ter um olhar crítico para as questões relacionadas aos direitos humanos.

A necessidade de o(a) professor(a) realizar formações continuadas surge pelas mudanças do contexto social, as quais afetam a escola, pois esta, enquanto instituição, é construída socialmente e sofre influências de vários aspectos da sociedade. Nessa perspectiva, Schmidt e Garcia (2008) apontam que "a escola é um resultado de determinada ação social que pode ser de dominação e conflito e, também, como um lugar de ações e relações” (SCHIMIDT; GARCIA, 2008, p. 42).

Defendemos, pois, que para compreender o mundo social e intervir sobre ele, e não simplesmente responder aos seus imperativos, é necessário identificar as "estruturas em funcionamento que geram os eventos, as aparências e os discursos" (MORAES, 2009, p. 594). Nesse sentido, compreende-se que o mundo social é “estruturado, diferenciado e em mudança, enfim, histórico" (MORAES, 2009, p. 597).

Partindo dessa premissa, é necessário compreender as mudanças da sociedade ao longo da história, sendo que a partir delas surgem novas demandas para a educação escolar. Imbernón (2016) explica que, “ao longo do século XX e até ao atual momento do século XXI, a sociedade tornou-se mais complexa; portanto, exercer a função de professor também assumiu grandes parcelas de complexidade" (IMBERNÓN, 2016, 
p. 34). Ele também considera que tanto as funções do(a) professor(a) da educação básica como os(as) estudantes mudaram ao longo da história.

Para esse autor, muitos aspectos da sociedade só poderão ser aprendidos e compreendidos no contexto escolar, sendo que um deles é o de ser cidadão que tenha respeito em relação a si mesmo e em relação aos outros, sejam eles quem forem, bem como o respeito pelo ambiente em que vivem. Complementa, ainda, pontuando que será fundamental desenvolver nos(as) professores(as) e nas crianças "O respeito e a tolerância, dois conceitos que terão um papel fundamental no mundo que construímos dia a dia” (IMBERNÓN, 2016, p. 52).

Dessa forma, é importante que questões atuais e sociais, como a temática Direitos Humanos, sejam discutidas em formações continuadas de professores(as). Para Imbernón (2016), no século XXI, o(a) professor(a) precisa participar ativa e criticamente em seu contexto e, também, "transmitir aos futuros cidadãos e cidadãs certos valores e certas formas de comportamento democrático, igualitário, que respeite a diversidade cultural e social, o meio ambiente, etc." (IMBERNÓN, 2016, p. 52). Nesse sentido, as ideias apontadas por Imbernón (2016) se aproximam de uma visão de educação voltada para os Direitos Humanos. Nessa perspectiva, defendemos ser fundamental que os(as) docentes possam conhecer sobre a temática Direitos Humanos nas formações continuadas, pois é possível estabelecer a inter-relação entre as ciências naturais e as ciências humanas. É fundamental se ter uma visão mais crítica para a sociedade, no sentido de se indignar com aquilo que é considerado por muitas pessoas como normal e, dessa forma, instigar os (as) professores (as) à perceberem que, mesmo em nossa comunicação verbal, podemos estar violando os direitos humanos (OLIVEIRA; QUEIROZ, 2015).

Portanto, consideramos que esse "olhar crítico" precisa ser desenvolvido nas formações continuadas, para que os (as) professores (as) observem que muitas falas, ações, atitudes, são imbuídas de preconceito e discriminação, as quais tantas vezes, não são perceptíveis por falta de conhecimento da realidade social em que vivem. Nesse sentido, várias temáticas podem ser discutidas em formações continuadas para que de fato as mesmas contribuam para desenvolver o olhar docente para as injustiças sociais, como gênero, sexo, sexualidade, cultura, religião, orientação sexual, e outras. 
Sendo assim, considera-se fundamental que professores(as) possam realizar cursos de formação continuada, que sejam espaços para o desenvolvimento profissional, para que de fato possam refletir sobre essas disposições já incorporadas, as quais são construídas pelo capital social, cultural e econômico (BOURDIEU, 2015). É necessário que se promovam reflexões sobre as temáticas discutidas nos encontros de formação continuada, relacionando-as com questões reais da sociedade, "questões mais amplas sobre educação em sociedades democráticas" (ZEICHNER, 2008, p. 545).

Candau e Sacavino (2013, p. 64) apontam que as formações de professores(as) voltadas para temática Direitos Humanos precisam "transformar mentalidades, atitudes, comportamentos, dinâmicas organizacionais e práticas cotidianas dos diferentes atores, individuais e coletivos, e das organizações sociais e educativas". Destacam que é necessário um enfoque metodológico que privilegie estratégias ativas, a fim de estimular a articulação da prática com a teoria, "elementos cognitivos, afetivos e envolvimento em práticas sociais concretas" (CANDAU; SACAVINO, 2013, p. 64). É importante compreender que os(as) docentes não podem ser entendidos(as) como consumidores(as) de conhecimento, mas como sujeitos capazes de produzi-lo e de valorizar o conhecimento desenvolvido por outros. A "formação de professores deve promover o contexto para o desenvolvimento intelectual, social e emocional dos professores” (MARCELO GARCIA, 1999, p. 30).

Neste artigo, defendemos que os(as) professores(as) dos anos iniciais do ensino fundamental precisam conhecer e compreender sobre os direitos humanos e articular essa temática aos conteúdos de Ciências Naturais. Avaliamos que as formações voltadas para o ensino de Ciências precisam considerar temáticas que se aproximem de uma educação mais humana e mais sensível às condições dos sujeitos, as quais, muitas vezes, ferem a dignidade humana.

Defendemos, também, que o ensino de Ciências Naturais tenha como objetivo a formação do(a) estudante em todos os seus aspectos. Nesse sentido, o ensino de Ciências Naturais precisa ser articulado às questões sociais, principalmente, as que são consideradas de urgência social, para a formação de uma sociedade mais humana, justa e democrática. Sendo assim, no próximo tópico será discutido sobre a formação 
de professores(as), que atuam no ensino de Ciências Naturais nos anos iniciais do Ensino Fundamental, voltada para os Direitos Humanos.

\section{Formação de professores(as) voltada para os Direitos Humanos e Ensino de Ciências Naturais}

Compreendemos que a escola, como está organizada hoje, muitas vezes reproduz a ordem social vigente, reforçando a exclusão dos estudantes devido à própria cultura escolar (BOURDIEU; PASSERON, 2014; GIMENO SACRISTÁN, 2017). Nesse sentido, o sistema educativo acaba avigorando, a partir do próprio efeito das relações simbólicas, a reprodução das relações de força entre classes (BOURDIEU; PASSERON, 2014). Assim, muitas práticas realizadas no contexto escolar como, por exemplo, o conteúdo que é desenvolvido, a forma como este conteúdo é trabalhado, as relações professor-aluno, o processo de avaliação, a organização dos horários, entre outros, estão fundamentados em uma cultura dominante, a qual muitas vezes é legitimada como a única e a mais importante no contexto social. Portanto, muitas ações realizadas na escola poderão ter como objetivo o não acolhimento aos estudantes das classes menos favorecidas ou aos estudantes de diferentes etnias, os quais possuem uma cultura que não é reconhecida como legítima e que também não é valorizada pela escola. Nessa perspectiva, Bourdieu (2015) destaca:

A cultura da elite é tão próxima da cultura escolar que as crianças originárias de um meio pequeno-burguês (ou, a fortiori, camponês e operário) não podem adquirir, senão penosamente, o que é herdado pelos filhos das classes cultivadas: o estilo, o bom-gosto, o talento, em sínteses, essas atitudes e aptidões que só aparecem naturais e naturalmente exigíveis dos membros das classes cultivadas, porque constituem a "cultura" (no sentido empregado pelos etnólogos) dessa classe (BOURDIEU, 2015, p. 61).

Os(as) professores(as) são frutos desse sistema de ensino, ou seja, sua formação ocorreu a partir de um sistema educacional que reproduzia - e ainda reproduz - a ordem social vigente, sem questionamentos ou formas diferenciadas de se educar. Esses saberes construídos, ao longo da vida escolar, pelos professores e professoras influenciam sua prática profissional, muitas vezes exercendo práticas e ações que reforçam a exclusão e o afastamento do estudante do contexto escolar. 
Por isso, consideramos que desvelar esses pressupostos em formações continuadas, em um processo de reflexão, a partir da prática e na prática, poderá ser uma forma de o professor reestruturar ações que sejam mais coerentes à educação voltada aos Direitos Humanos. Beineke (2012) aponta que "é por meio da reflexão que o profissional aprende a lidar com as situações únicas, incertas e conflituosas das relações estabelecidas em espaços de produção do conhecimento, seu mundo prático, o qual pode incluir, também, o diálogo reflexivo com a ciência" (BEINEKE, 2012, p. 192).

Assim, é importante que se criem espaços para que os(as) docentes possam ter consciência sobre os valores que organizam as suas práticas e compreendam seus efeitos em uma perspectiva de mudanças da realidade educativa e social, sendo isso muito mais do que uma simples reflexão sobre suas ações. Para isso, é necessário buscar a "coerência com esquemas culturais e filosóficos dentro de um modelo educativo, social e dentro de sua própria projeção histórica na vida dos homens e dos grupos sociais" (GIMENO SACRISTÁN, 2017, p. 269).

Contreras (2002) destaca sobre a importância em relação ao distanciamento crítico e reflexivo dos(as) professores para que seja possível tornar o processo de aprendizagem dos(as) estudantes um lugar para a uma formação para a participação "ativa e autônoma na vida pública, bem como para a configuração de sua vida pessoal" (CONTRERAS, 2002, p. 2015). Consideramos que as formações continuadas de professores(as) de Ciências Naturais, que sejam fundamentadas nos princípios de uma Educação em Direitos Humanos, precisam estar pautadas em dois pilares fundamentais, quais sejam, na formação ética do(a) professor(a) e no seu autoconhecimento.

Em relação à formação ética, Imbernón (2016) pontua que essa questão nunca foi uma preocupação no campo educacional, mais especificamente sobre a formação de professores, pois havia uma maior preocupação com as questões voltadas à aprendizagem dos(as) estudantes. Esse autor também destaca que é "como se a formação de professores que se realiza, tanto a inicial como permanente, tivesse de ser ética por natureza, por si mesma, partindo dessa bondade inata" (IMBERNÓN, 2016, p. 171). Nesse sentido, o autor salienta que se deve refletir sobre a ética na 
formação de docentes, pois são esses profissionais que depois de formados introduzirão a ética aos seus estudantes. E ainda ressalta:

E não nos esqueçamos de que professores e professoras ensinam mais pelo que viram e pelo que lhes ensinaram do que pelo modo como deveriam fazê-lo. Se não introduzimos a ética na formação do professorado, como se pode realizar depois um ensinamento ético no ensino da infância e da juventude? (IMBERNÓN, 2016, p. 171).

Diante dessa pergunta do autor, compreendemos que questões éticas precisam estar presentes, tanto na formação inicial como na formação continuada dos(as) professores(as), pois consideramos isso fundamental para que os(as) docentes possam refletir sobre suas ações e que contribuam em suas práticas pedagógicas para a construção de sociedades mais humanas, justas e solidárias. Para o autor supracitado, é importante a necessidade de desenvolver competências éticas na formação docente para que isso faça parte de sua identidade e para que os professores e professoras saibam "formar cidadãos que trabalhem em busca do bem comum e da democracia" (IMBERNÓN, 2016, p. 172). Assim, a formação ética contribui para desenvolver o "bem comum coletivo e as relações positivas com os outros e com o contexto" (IMBERNÓN, 2016, p. 172).

Arroyo (2015) faz alguns questionamentos importantes sobre a formação ética nos cursos de licenciaturas e de pedagogia:

\begin{abstract}
Nos cursos de formação, deveria ser dada centralidade a entender desde o pensamento educativo as catastróficas consequências para a formação ética, cultural e humana, produzidas pela pobreza, fome, marginalização das crianças, dos adolescentes, alunos das escolas populares. Dezessete milhões de crianças e adolescentes levam cada dia às escolas as vivências desumanizantes de ser condenados com suas famílias e sobreviver na pobreza extrema. Os cursos de formação nas licenciaturas e na pedagogia fornecem pautas teóricas e práticas para compreender essas catastróficas consequências para nelas intervir como educadores(as)? Quando o mal se banaliza, que condutas esperar de crianças, adolescentes e jovens expostos a essa banalização? Os cursos de formação poderiam cultivar nos profissionais da educação desses educandos a capacidade de ler com perspicácia e profundidade ética essas perversas consequências antiéticas (ARROYO, 2015, p. 30).
\end{abstract}

Nesse sentido, apreendemos que a formação ética precisa ser compreendida tendo como cerne a realidade que várias crianças e jovens enfrentam na sociedade, repensando práticas escolares muitas vezes pautadas no preconceito e não aceitação às diferenças. Consideramos que conhecer as crianças e jovens e questionar as consequências dessas realidades ímpares para a formação ética em uma sociedade 
desigual como a nossa é fundamental para que professores(as) não tenham visões estereotipadas em relação aos seus(suas) estudantes e, sim, que os(as) acolham nessas diferenças. Arroyo (2015) salienta que para um(a) professor(a) seria uma postura ética inicial perguntar como sobrevivem muitos estudantes "em situações tão desumanizantes e, sobretudo, como preservam sua humanidade a ponto de voltar cada dia à procura do saber e da educação. Indagar também pelas sequelas que deixa em sua formação ética a experiência tão prematura de processos brutais de desumanização" (ARROYO, 2015, p. 35). Nessa perspectiva, ter uma postura ética é conhecer seus(suas) estudantes e não os rotular "entre os bons e os maus, os dignos e os viciados, mas vê-los como personagens éticos em conflitos éticos demasiado dramáticos para o seu desenvolvimento humano e moral. Acreditar que nesses brutais processos de desumanização a que são submetidos o humano é viável” (ARROYO, 2015, p. 35).

Contreras (2002) ressalta que, além das conquistas acadêmicas, o(a) professor(a) precisa estar comprometido com seus estudantes em seu desenvolvimento enquanto pessoas, e destaca que é "preciso entender o avanço na aprendizagem de seus alunos, enquanto não se pode esquecer das necessidades e do reconhecimento do valor que, como pessoas, lhe merece todo o alunado" (CONTRERAS, 2002, p. 76). Para esse autor, uma das dimensões da profissionalidade docente é a obrigação moral, sendo considerada a moralidade como algo não isolado, mas sim um fenômeno social. Portanto, seria o resultado das vidas das pessoas em comunidade, na qual é necessário resolver problemas que atingem a vida humana e seu desenvolvimento e que é moralmente adequado para cada situação. Nesse sentido, a educação não pode ser encarada como algo individual e privado do(a) professor(a), e sim como "uma ocupação socialmente encomendada e responsabilizada publicamente" (CONTRERAS, 2002, p. 79). O autor complementa que as práticas dos(as) professores(as) não deveriam ser isoladas, mas sim partilhadas. "Somente nos contextos sociais, públicos, a obrigação ética pode alcançar sua dimensão adequada" (CONTRERAS, 2002, p. 79), no sentido de que esse professor(a) possa, em seu contexto profissional, compartilhar problemas, discutir princípios, buscar alternativas e soluções, organizar sua própria ação, etc. e também demonstrar seu compromisso nas decisões sobre o ensino. 
Para Imbernón (2016, p. 173), a formação ética dos(as) professores(as) precisa estar pautada na construção e apreciação de específicos valores que levam a uma "moral educacional, a desaprender valores que cultivam seres humanos competitivos, isolados e não solidários", para que, assim, os(as) professores(as) possam em sala de aula contribuir para o desenvolvimento de uma cidadania ativa baseada em valores democráticos, buscando a inclusão social e desenvolver o interesse e a disposição para se envolverem em projetos comunitários que tenham como cerne o comprometimento com a dignidade de todos os seres humanos. Na perspectiva do autor, para que a formação docente tenha como propósito o desenvolvimento de valores éticos e morais, ela não deveria estar apenas baseada na transmissão de conhecimentos, ou seja, no repasse dos conteúdos dos diferentes componentes curriculares, mas seria importante e necessário, também, que os conhecimentos subjetivos fossem considerados importantes, como as emoções, as atitudes e os sentimentos. Sendo assim, mais "que saber muita didática de matemática, é preciso assumir um compromisso que vá além do meramente técnico e que deve alcançar os âmbitos do pessoal e do grupal” (IMBERNÓN, 2016, p. 174).

Neste sentido, a preocupação é a maneira como "formar pessoas para que formem pessoas" (IMBERNÓN, 2016, p. 174), pois a maneira como os professores serão formados irá influenciar suas práticas e suas reflexões sobre o papel da educação para a formação humana do educando. Sendo assim, consideramos que quando nas formações continuadas há um olhar voltado para a formação ética e moral dos professores, estes poderão rever suas atitudes, seus valores e suas formas de pensar no contexto escolar, contribuindo assim para que ações, como o cuidar e o educar, estejam presentes nas práticas realizadas na sala de aula e no contexto geral da escola.

Para Imbernón (2016), é fundamental que a formação docente seja gerada por uma motivação intrínseca, relacionada com a função de ser professor ou professora, porque essa formação é muito mais complicada para aquele(a) docente que se encontra em um ambiente desmotivador e passivo. Imbernón (2016) destaca que:

[...] quanto melhor a cultura dos professores e melhor seu ambiente de trabalho, menos vulneráveis ele serão ao que vem de fora, e isso não interessa a muitos governos. É melhor manter o professorado subjugado e empobrecido para que seja mais vulnerável e menos crítico em relação às decisões políticas e sociais. E professorado subjugado transmite os valores desejados pelo poder instituído (IMBERNÓN, 2016, p. 175). 
Nesse sentido, formar ética e moralmente os(as) professores(as), em formações iniciais e continuadas, contribui para que este profissional questione valores muitas vezes disseminados pelas decisões políticas e sociais, desvelando questões implícitas presentes nestas decisões.

A formação ética, para Imbernón (2016), é uma formação baseada no ensino de cidadanias, no plural, no sentido de que os professores, tanto individual como coletivamente, as desenvolvam de forma transversal em sua atividade docente. Também está fundamentada no desenvolvimento de habilidades sociais que possibilitem o entendimento da realidade e que haja uma leitura crítica dos acontecimentos do entorno. E que, além disso, seja formada "na independência de opinião, de raciocínio, de deliberação e de diálogo construtivo; que ajuda a transformar as relações das pessoas com as sensibilidades democráticas, sociais, paritárias, interculturais e ambientais" (IMBERNÓN, 2016, p. 178). Para o autor, a formação ética do(a) professor(a) não pode ser considerada como algo que já está implícito na formação docente, mas sim como algo que precisa ser construído e reconstruído. Por esse motivo, consideramos que as formações continuadas podem ser espaços para essa construção e reconstrução necessárias para um olhar mais crítico para a sociedade e para as relações humanas, no sentido de problematizar disposições construídas ao longo do processo de socialização do professor e da professora. Vivemos em uma sociedade marcada pela violência simbólica e pelas injustiças sociais, portanto, problematizar essas questões é de suma importância para se mudar posturas e formas de pensar o contexto social e também as relações escolares.

Compreendemos que as formações também poderão ser momentos para que o(a) professor(a) se autoconheça, a fim de entender a realidade múltipla que o(a) constitui, “indagando as dimensões não reconhecidas nem integradas, compreendendo nossas experiências de marginalização e de opressão, e tratando de descobrir as dissonâncias entre nossas diferentes dimensões pessoais" (CONTRERAS, 2002, p. 210). De acordo com Contreras (2002), para se autoconhecer é necessário compreender a forma pela qual os sentimentos influem nas compreensões e atuações e vice-versa, e pontua que: 
Não poderemos, por exemplo, compreender bem o que é a intolerância se não compreendemos quais são as nossas intolerâncias, ou seja, se não compreendermos de que intolerâncias somos vítimas, em quais relações cotidianas tomamos parte que são intolerantes, mas também no que nós somos intolerantes conosco, que dimensões de nossa vida pessoal e de nossas relações próximas resistimos a reconhecer ou nos é difícil aceitar e integrar (CONTRERAS, 2002, p. 208).

Para esse autor, é importante que houvesse um movimento de olhar, tanto para fora como para dentro de nós mesmos, ou seja, para o interior. Assim, “descobrir a parcialidade ou sensibilizar-nos diante de dimensões da vida humana que não se deixam reduzir a uma compreensão puramente racional ou ideologicamente correta" (CONTRERAS, 2002, p. 208) pode ser uma forma de sensibilizarmos a partir dessa ida ao nosso interior, de nosso próprio ser pessoal, dando origem a um processo de autorreflexão. Para Contreras, questões relacionadas à marginalização, à não aceitação do outro e à opressão não são questões vistas apenas no meio exterior, mas,

[...] que também no nosso interior podemos reconhecer facetas, sentimentos, desejos aplacados, e poderemos compreender (cognitiva e empaticamente) o significado e a experiência da rejeição, da separação, da intolerância às diferenças, da submissão a ideologias sociais, porque estas são experiências e sentimentos íntimos. Desta maneira, a autonomia segue ligada não apenas ao ineludível compromisso moral nos juízos e decisões profissionais, mas também ao autoconhecimento (CONTRERAS, 2002, p. 208).

Contreras (2002) pontua que a vida emotiva não é valorizada na vida profissional, pois a ideia de ser um profissional está muitas vezes atrelada à capacidade de distanciamento afetivo das situações e pessoas com as quais interage no trabalho — isto significa o não envolvimento. E destaca que, nessa perspectiva técnica, os sentimentos são considerados como inconvenientes, de modo a alterar o "diagnóstico ou a aplicação racional dos métodos de ensino" (CONTRERAS, 2002, p. 209). No entanto, o modelo reflexivo possibilita que o(a) professor(a) reconheça, a partir de análises, as perspectivas e os valores pessoais que sustentam suas práticas. Nesse sentido, “a dimensão afetiva e emocional está na base de nossos valores e se encontra no sentimento pela dor dos outros, não podemos esperar desenvolver uma prática autônoma, comprometida com determinados valores, sem prestar atenção aos nossos sentimentos" (CONTRERAS, 2002, p. 210).

É importante compreender que o processo de autoconhecimento não acontece de forma isolada, mas nas relações. Mesmo que essa ideia de 
autoconhecimento tenha como cerne a busca interior, é importante que haja "[...] a descentralização, o conseguir se ver de fora, de outras posições e com outros princípios. E isso significa, no mínimo, ver-se a partir de diversos pontos de vista, ou a partir da experiência de relacionamentos com as pessoas e de nosso entendimento ou não dos outros" (CONTRERAS, 2002, p. 211). Consideramos que as formações podem ser momentos importantes para o desenvolvimento do autoconhecimento, a fim de refletir sobre si, olhar para seu interior e perceber-se como responsável pela aprendizagem dos(as) estudantes.

Avaliamos que a formação baseada no autoconhecimento contribui para que os(as) professores(as) tomem decisões, tanto em seu contexto de trabalho como nas interações estabelecidas com seus(suas) alunos(as) e nas relações deles(as) com os conteúdos, de forma mais ética e comprometida com a educação, principalmente voltada para a formação de uma cultura em direitos humanos. Desse mesmo modo, as formações baseadas no autoconhecimento do(a) professor(a), tendo como foco não apenas o conhecimento técnico, mas também suas subjetividades, emoções e sentimentos, em um processo reflexivo, contribuem para que disposições construídas ao longo do processo de socialização do agente, a partir das distintas instituições nas quais fizeram e fazem parte, possam ser repensadas e reelaboradas, visando uma formação ética, política e crítica, que desenvolva práticas pedagógicas mais voltadas para uma Educação em Direitos Humanos.

Candau e Sacavino (2013) destacam que é importante que nas formações de professores(as) voltadas para a EDH haja uma metodologia diferenciada, que não seja baseada no "ensino frontal", ou seja, em exposições orais sobre o conteúdo do curso, e com poucos diálogos, pois essa estratégia poderá atuar mais especificamente no campo cognitivo. Nesse sentido, as autoras destacam sobre a importância da participação ativa dos(as) professores(as) e que sejam utilizadas diferentes linguagens e a promoção do diálogo entre os diferentes saberes, tendo como referência fundamental a realidade social e as experiências dos partícipes. Destacam que se deve ter especial atenção aos relatos de "histórias de vida relacionadas às violações ou à defesa dos Direitos Humanos, apresentadas pelos próprios participantes, através de entrevistas realizadas com determinadas pessoas indicadas pelo grupo ou através de matérias de jornais e outros meios de comunicação" (CANDAU; SACAVINO, 2013, p. 13). 
Entendemos que a formação continuada de professores(as) dos anos iniciais do ensino fundamental que ensinam ciências naturais, tendo como pilares a formação ética do(a) professor (a) e o seu autoconhecimento, poderá ser um momento importante para que os(as) docentes reflitam sobre os conteúdos que serão desenvolvidos na sala de aula e como eles podem se articular com temáticas relacionadas aos direitos humanos, e que também possam desenvolver uma visão crítica para os livros didáticos, percebendo as questões relacionadas aos estereótipos que esses podem apresentar e identificando como as diferenças e diversidades se apresentam nesses materiais didáticos, partindo de princípios éticos. Compreendemos que os(as) professores(as) precisam usar a criatividade para planejar propostas no ensino de ciências naturais que tenham significado para as crianças dessa etapa de ensino, considerando também suas realidades concretas, suas curiosidades e seus conhecimentos prévios, articulando-os como os conteúdos de ciências naturais.

As discussões realizadas na formação de professores(as) de ciências naturais precisam considerar as especificidades dos anos iniciais do ensino fundamental, sendo uma dessas especificidades a formação acadêmica desses(as) professores(as) que atuam nessa etapa de ensino. Na maioria das vezes, esse(a) profissional é formado(a) em Pedagogia, e não em ciências da natureza, por isso, a importância de esse(a) professor(a) conhecer os conteúdos de ciências naturais para poder realizar a transposição didática, bem como articulá-los as temáticas relacionadas aos direitos humanos. Outra especificidade dessa etapa é a idade dos(as) estudantes, pois é importante que o ensino realizado pelo(a) docente considere as curiosidades das crianças diante do conhecimento científico e que articule essas curiosidades com os conteúdos de ciências naturais. Para isso, destacamos que nessa faixa etária deve ser considerada a atividade lúdica, a qual pode ser utilizada como "promotora de aprendizagem", aproximando os(as) estudantes do conhecimento científico. Portanto, a prática lúdica pode constituir "um importante recurso para que o professor desenvolva a habilidade de resolução de problemas, favorecendo o aprimoramento de conceitos e atendimento das dúvidas daqueles que ainda estão em processo de desenvolvimento" (BUENO et al., 2017, p. 27).

Logo, compreendemos que, nessa faixa etária, o ensino de ciências precisa ser pautado em atividades significativas e mobilizadoras de aprendizagens em relação ao 
conhecimento científico, e nas formações continuadas também devem estar presentes o caráter lúdico, relacionando a prática e a teoria. Avaliamos que é fundamental que as diferentes linguagens estejam presentes nas estratégias metodológicas dos(as) professores(as) de ciências naturais, como a música, a literatura infantil, o teatro, o desenho, a escrita, a verbal, a tecnológica, etc., no intuito de tornar as aulas de ciências mais atrativas para as crianças que estão tendo os primeiros contatos com a linguagem científica formal. Entendemos que as crianças expressam-se utilizando "várias linguagens com as quais constroem a si mesmas e as culturas nas quais estão inseridas levando-as ao encontro entre palavras, choros, sons, movimentos, traçados, pinturas, todos imbricados em ricas manifestações” (GOBBI, 2010, p. 1). Gobbi (2010) destaca que compreender sobre as linguagens utilizadas pelas crianças para se expressarem, "bem como aquelas usadas pelos adultos, significa estar junto com elas e perceber suas características de acordo com gênero, classe social, etnia, faixa etária a qual pertencem" (GOBBI, 2010, p. 2). Por isso, consideramos que essas linguagens precisam ser valorizadas nas formações de professores(as) que atuam nos anos iniciais do ensino fundamental no ensino de ciências, compreendendo que as crianças utilizam essas linguagens para interpelar o mundo.

Os espaços de formação de professores(as) precisam ser planejados para que possam ser momentos de reflexão sobre as práticas que são realizadas na sala de aula e, também, para que os/as formadores(as) tenham uma escuta sensível ao que os(as) professores(as) trazem de experiências reais, tanto como agentes do contexto social quanto como professores(as) atuantes no ensino de ciências naturais nos anos iniciais, em uma determinada escola, com determinadas práticas institucionalizadas. Para Pizarro, Barros e Lopes Junior (2016), é importante olhar para o(a) professor(a) dessa etapa de ensino para além do que ele(a) ignora, valorizando o que ele(a) já sabe e avançando com ele(a) para novos entendimentos "sobre como aprender, ensinar e avaliar em Ciências" (PIZARRO; BARROS; LOPES JUNIOR, 2016, p. 443). Considerar as subjetividades docentes, suas problemáticas, seus desafios e avanços também faz parte da formação docente e de seu desenvolvimento profissional.

Por conseguinte, entendemos que nas formações dos(as) professores(as) de ciências naturais, voltadas para uma educação que tenha como objetivo a formação humana e os princípios de uma EDH, precisa ser priorizada a ética e oportunizado o 
autoconhecimento, e que os(as) formadores(as) de professores(as) precisam considerar o saber fazer prático, a fundamentação teórica das práticas no ensino de ciências naturais e a análise das práticas institucionalizadas (GIMENO SACRISTÁN, 2017).

\section{Considerações finais}

O objetivo do artigo foi discutir sobre a formação continuada de professores de Ciências Naturais, dos anos iniciais do ensino fundamental, voltada à formação ética e ao autoconhecimento, tendo como princípio uma educação em Direitos Humanos. Consideramos que educação em Direitos Humanos deve ser uma temática desenvolvida nos diferentes componentes curriculares, no sentido de contribuir para que os estudantes desenvolvam habilidades e competências, o senso crítico, o respeito à dignidade humana e que aprendam a tomar decisões frentes aos desafios da sociedade. Para que isso seja de fato concretizado, é necessário que todos(as) os(as) estudantes tenham uma educação de qualidade. A qualidade não se refere apenas ao(à) estudante ter acesso aos conhecimentos voltados para a leitura, para a escrita e para o cálculo, mas também que este tenha acesso aos conhecimentos imprescindíveis para viver em sociedade, e que "seja fortalecida a sua capacidade de desfrutar de todos os direitos humanos e de fomentar uma cultura em que prevaleçam os valores dos direitos humanos" (UNESCO, 2012, p. 4). No entanto, defendemos, neste trabalho, a articulação de temáticas de Direitos Humanos ao ensino de Ciências Naturais nos anos iniciais do ensino fundamental porque consideramos que esta articulação é possível e viável, e precisa ser discutida nas formações continuadas de professores dessa etapa de ensino, pois os(as) professores(as) se constituem no processo de socialização, a partir de sua história e suas experiências, e isso irá influenciar suas percepções e entendimentos em relação ao que são direitos humanos e o que é uma Educação em Direitos Humanos. Diante disso, consideramos que as formações continuadas precisam desenvolver ações relacionadas a essa temática e que essas discussões precisam estar pautadas no desenvolvimento ético e humano dos(as) professores(as), contribuindo para uma visão mais crítica do contexto social, bem como baseada nas relações humanas, nas quais empatia, tolerância e respeito sejam os focos das discussões. Assim, as formações precisam ser baseadas no processo de reflexão e autorreflexão para o 
autoconhecimento. Desse modo, consideramos que as formações continuadas de professores(as) de Ciências Naturais, fundamentadas nos princípios de uma Educação em Direitos Humanos, precisam estar pautadas em dois pilares fundamentais, quais sejam, a formação ética do professor e o autoconhecimento, contribuindo assim para mudanças no babitus. Além desses pilares, é importante que as formações relacionadas ao ensino de ciências naturais e direitos humanos considerem as especificidades dos anos iniciais do ensino fundamental, como a formação inicial dos(as) docentes, a criança e suas linguagens e as estratégias didáticas.

Avaliamos que as formações baseadas no autoconhecimento do professor, tendo como foco não apenas o conhecimento técnico, mas também suas subjetividades, emoções, sentimentos, em um processo reflexivo e dialógico, contribuem para que disposições construídas ao longo do processo de socialização do agente, a partir das distintas instituições nas quais fizeram e fazem parte, possam ser repensadas e reelaboradas, visando uma formação ética, política e crítica que leve para práticas pedagógicas mais voltadas para uma Educação em Direitos Humanos.

Em relação às implicações para a área de Ensino de Ciências, destacamos que este estudo teórico aponta para a necessidade de pesquisas empíricas, no sentido de avaliar se e como nas formações continuadas de professores(as) dos anos iniciais da educação básica tem sido considerada a formação ética e para o autoconhecimento, tendo como princípio uma Educação em Direitos Humanos. Também se mostram necessários estudos sobre como a formação inicial de professores(as) dos anos iniciais tem contemplado em seus processos formativos a Educação em Direitos Humanos e sua articulação ao ensino de Ciências Naturais.

\section{Referências}

ARROYO, M. Conhecimento, Ética, Educação, Pesquisa. Revista E-Curriculum, São Paulo, v. 2, n. 2, p. 1-24, 2007.

ARroyO, M. O humano é viável? É educável? Revista Pedagógica, Chapecó, v. 17, n. 35, p. 21-40, maio/ago. 2015.

BRASIL. Ministério da Educação. Base Nacional Comum Curricular. Brasília: MEC, 2017.

BEINEKE, V. A reflexão sobre a prática na pesquisa e formação de professor de música. Caderno de Pesquisa, v. 42, n. 145, p. 180-203, jan./abr. 2012. 
BERGER, P. L.; LUCKMANN, T. A construção social da realidade. 24. ed. Petrópolis: Vozes, 2014.

BONFIM, H. C. C.; GUIMARÃES, O. M. Articulação entre ciências naturais e direitos humanos em uma perspectiva para a formação humana. Revista Brasileira de Pesquisa em Educação em Ciências, v. 20, p. 949-974.

BOURDIEU, P. Esboço de uma teoria da prática. In: ORTIZ, R. (org.). A sociologia de Pierre Bourdieu. Trad. Paula Montero e Alicia Auzmendi. São Paulo: Olho d’água, 2003. p. 39-72.

BOURDIEU, P. Razões práticas: sobre a teoria da ação. 9. ed. Campinas, SP: Papirus, 2011.

BOURDIEU, P. O senso Prático. 3. ed. Rio de Janeiro: Vozes, 2013.

BOURDIEU, P.; PASSERON, J. A reproducão: elementos para uma teoria do sistema de ensino. 7. ed. Rio de Janeiro: Vozes, 2014.

BOURDIEU, P. A Escola Conservadora: as desigualdades frente à escola e à cultura. In: NOGUEIRA, M.A.; CATANI, A. (orgs.). Escritos da Educaşão. 16. ed. Petrópolis: Vozes: 2015. p. 44-72.

BUENO, N. M. N. et al. Jogo didático para ensino de ciências: batalha das grandes epidemias mundiais. In: CRISOSTIMO, A. L.; KIEL, C. A. O lúdico e o ensino de ciências: saberes do cotidiano. Guarapuava: Ed. da Unicentro, 2017. p. 27-39.

CANDAU, V. M.; SACAVINO, S. B. Educação em Direitos Humanos e formação de educadores. Educação, Porto Alegre, v. 36, n. 1, p. 59-66, jan./abr. 2013.

CARVALHO, L. O. et al. Metodologia cientifica: teoria e aplicação na educação a distância. Petrolina: Universidade Federal do Vale do São Francisco, 2019.

CONTRERAS, J. Autonomia de professores. 2. ed. São Paulo: Cortez, 2002.

GIMENO SACRISTÁN, J. Poderes instáveis em educação. Porto Alegre: Artes Médicas Sul, 1999.

GIMENO SACRISTÁN, J. O currículo: uma reflexão sobre a prática. 3. ed. Porto Alegre: Penso, 2017.

GOBBI, M. Múltiplas linguagens de meninos e meninas no cotidiano da educação infantil. In: SEMINÁRIO NACIONAL: CURRÍCULO EM MOVIMENTO, 1., 2010, Belo Horizonte. Anais... Belo Horizonte: Perspectivas Atuais, 2010. p. 1-21.

HEY, A. P. Estrutura (social e mental). In: CATANI, A. M. et al. Vocabulário Bourdieu. Belo Horizonte: Autêntica Editora, 2017. p. 191-192.

IMBERNÓN, F. Qualidade do ensino e formação do professorado: uma mudança necessária. São Paulo: Cortez, 2016.

MORAES, M. C. M. de. A teoria tem consequência: Indagações sobre o conhecimento no campo da educação. Educ. Soc., v. 30, n. 107, p. 585-607, maio/ago. 2009.

MARCELO GARCIA, C. Formação de professores. Para uma mudança educativa. 2. ed. Porto: Porto Editora, 1999. 
OLIVEIRA, R. D. V. L. de; QUEIROZ, G. R. P. C. (org.). Olhares sobre a (in)diferença: forma-se professores de ciências a partir de uma perspectiva de educação em direitos humanos. São Paulo: Editora Livraria da Física, 2015.

PENNA, M. G. de O. Origem social de professores e aspectos da prática docente. Educação. Porto Alegre, v. 35, n. 2, p. 199-2017, 2012.

PIZARRO, M. V.; BARROS, R. C. dos S. N.; LOPES JUNIOR, J. Os professores dos anos iniciais e o ensino de Ciências: uma relação de empenho e desafios no contexto da implantação de Expectativas de Aprendizagem para Ciências. Revista Brasileira de Pesquisa em Educação em Ciências, v. 16, n. 2, p. 421-448, ago. 2016.

SETTON, M. da G. J. A teoria do habitus em Pierre Bourdieu. Revista Brasileira de Educação, n. 20, p. 60-70, maio/ago. 2002a.

SETTON, M. da G. J. Família, escola e mídia: um campo com novas configurações. Educaşão e Pesquisa, São Paulo, v. 28, n. 1, p. 107-116, jan./jun. 2002b.

SETTON, M. da G. J. Socializạăão e cultura: ensaios teóricos. 2. ed. São Paulo: Annablume, 2016.

SCHMIDT, M. A.; GARCIA, T. M. F. B. História e Educação: diálogos em construção. In: SCHIMIDT, M. A.; GARCIA, T. M. F. B.; HORN, G. B. Diálogos e perspectivas de investigação. Ijuí: Unijuí, 2008. p. 29-48.

UNESCO. Plano de Ação: programa mundial para Educação em Direitos Humanos. Organização das Nações Unidas para a Educação, a Ciência e a Cultura. Brasília, 2012.

ZEICHNER, M. K. Uma análise crítica sobre a "reflexão" como conceito estruturante na formação docente. Educ. Soc., Campinas, v. 29, n. 103, p. 535-554, maio/ago. 2008. 